2017-08

\title{
Asymptotic residual stress distribution induced by multipass welding processes
}

\section{Ferro, $\mathrm{P}$}

http://hdl.handle.net/10026.1/9988

10.1016/j.jfatigue.2016.11.022

International Journal of Fatigue

All content in PEARL is protected by copyright law. Author manuscripts are made available in accordance with publisher policies. Please cite only the published version using the details provided on the item record or document. In the absence of an open licence (e.g. Creative Commons), permissions for further reuse of content should be sought from the publisher or author. 


\title{
Asymptotic residual stress distribution induced by multipass welding processes
}

\author{
P. Ferro ${ }^{1}$, F. Berto ${ }^{1,2}$, N.M. James ${ }^{3,4}$ \\ ${ }^{1}$ Department of Engineering and Management, University of Padova, Stradella San Nicola 3, 36100 \\ Vicenza, Italy \\ ${ }^{2}$ NTNU, Department of Engineering Design and Materials, Richard Birkelands vei 2b, 7491, \\ Trondheim, Norway \\ ${ }^{3}$ School of Marine Science and Engineering, University of Plymouth, Drake Circus, Plymouth, \\ England, United Kingdom \\ ${ }^{4}$ Department of Mechanical Engineering, Nelson Mandela Metropolitan University, Port Elizabeth, \\ South Africa
}

\begin{abstract}
In the high cycle fatigue (HCF) regime, the fatigue strength of welded joints is influenced by residual stresses (RS) induced during welding processes. If the weld toe is modelled via a sharp V-notch, the distribution of weld toe residual stress can be shown to be asymptotic with a singularity which follows either the linear-elastic or elastic-plastic solution depending on parameters that range across material properties, specimen clamping conditions, and the welding process. For thicker plates, multipass welding is used instead of single-pass welding to reduce the heat input and hence the width of the fusion zone (FZ) and heat-affected zone (HAZ). However, for a fixed plate thickness, the magnitude and extent of residual stresses near the weld toe will vary according to the number of passes used in the welding operation.

In this paper the influence of multipass welding on the residual stress field near the weld toe has been analysed using a combination of analytical and numerical techniques. It was found that the higher the number of weld passes, the higher the magnitude of the residual asymptotic stress field near the weld toe.
\end{abstract}

Keywords: residual stress, fatigue, notch stress intensity factors, multipass welding, numerical simulation

\section{Introduction}

In most engineering structures, the thickness of the plate necessitates the adoption of multipass welding to control distortion and microstructure across the welded joint, and because there are limits to the amount of metal that can be laid down in a single pass. The magnitude and distribution of residual stresses that result from multipass welding are both important to structural integrity and difficult to predict. The same issues arise in weld cladding where, for example, some $9 \mathrm{~mm}$ of austenitic steel cladding is laid down on the inner surface of ferritic steel reactor pressure vessels (RPV) to increase the long-term corrosion resistance of the ferritic steel. The cladding is laid down by submerged arc welding typically using a filler metal that is $60 \mathrm{~mm}$ by $0.5 \mathrm{~mm}$. The strip welding process used in the cladding operation induces significant residual stresses in the clad layer and in the RPV steel casing. In structural integrity terms it is important to characterise the magnitude and distribution of these residual stresses as they can impact upon the possibility of brittle fracture and stress corrosion cracking. A particular issue in measuring residual stresses at joints between dissimilar metals is the large variability often seen in the results obtained using different methods [1].

The relationships among joint preparation, weld process conditions, metallurgy and plate thickness have been investigated by many researchers over the years, and this paper will focus only on a very few illustrative examples drawn from this extensive literature. Murugan et al. [2] reported an experimental study of the thermal cycles and transverse residual stresses due to each welding pass in type 304 austenitic stainless steel and low carbon steel plates $6 \mathrm{~mm}, 8 \mathrm{~mm}$ and $12 \mathrm{~mm}$ in thickness. 
Residual stresses were measured on both sides of the plates after each pass using X-ray diffraction. The main conclusions from their work were that with an increase in number of weld passes, the peak tensile residual stresses gradually reduced on the root side and gradually increased in magnitude on the top side of the plate. The width of the residual stress distribution increases with increase in plate thickness. They also observed that, in general, for any specified peak temperature at the mid-plane of the plate thickness, the residual stress in low carbon steel was higher than in stainless steel of the same thickness.

A significant number of papers have reported numerical investigations of the residual stress distribution as a function of number of weld passes. For example, Liu, Zhang and Xue [3] have reported the results of a detailed finite element study of the pass-by-pass residual stresses in type 304L stainless steel pipes with an outer diameter of $680 \mathrm{~mm}$ and a wall thickness of $70 \mathrm{~mm}$, welded with 73 passes using a $0.8 \mathrm{~mm}$ diameter filler wire. Numerical modelling results were compared with experimental blind-hole drilling measurements of the surface stress at the end of welding. They observed a reasonable correlation between the surface measurements and the FE simulation data, although the numerical values for the hoop stress were considerably higher than the measured data. The authors attributed this to errors in the hole drilling technique once the residual stresses are higher than $50 \%$ of the yield strength. Their FE simulation demonstrated a steady evolution of the magnitude and extent of the through-thickness and hoop residual stresses with increase in number of welding passes. They also noted that the first few weld passes have a significant impact on the formation of the final residual stress distribution and that the value of the peak tensile stress remained unchanged once the weld groove had been filled to around $30-45 \%$ of the total wall thickness. Predicted peak tensile values of the hoop stress reached $600 \mathrm{MPa}$, significantly higher than the yield strength of 304L stainless steel.

Ueda et al. [4] considered the issue of strategic simulation analyses for manufacturing problems related to welding. They noted that in welding fabrication, the primary objectives are to minimise weld-induced stress/strain and deformation, and that applying weld constraint to limit deformation leads to a larger magnitude of induced residual stress/strain. In their paper they proposed that computational simulation and experiments should be performed before adopting any new fabrication procedure. The purpose of such a thermal elastic-plastic analysis is to analyse the welding phenomena at points where the largest stress and strain occur, so as to identify an optimum set of weld process parameters. Consideration of the influences of multipass welding and of thermo-metallurgical phenomena and transformations are obviously of primary importance in this approach.

The important role that metallurgical phase transformations and associated shape changes play in affecting the development of residual stresses was emphasised by Bhadeshia [5]. He outlined the design of alloys such that the deformation caused by bainite and martensite transformations eliminates residual stress, leading to extraordinary improvements in the fatigue life of constrained structural assemblies. It is clearly highly beneficial to optimally design welding fabrication in terms of both process parameters, e.g. heat input, preheat and interpass temperatures, as well as in metallurgical terms through consideration of filler metal alloy content, cooling rate and post-weld heat treatment (PWHT).

In contrast to this significant body of results obtained from numerical modelling and experimentation, analytical work is much scarcer in the literature, although several papers have recently been published that outline interesting new approaches. For instance, Das and Cleary [6] have presented a novel mesh-free Smoothed Particle Hydrodynamics (SPH) method for analysing the flow pattern of the filler metal in welding using a fully coupled three-dimensional elastoplastic and heat transfer analysis and the consequent plastic strain development and temperature distributions for a simple arc welding configuration. The authors state that the mesh-less and Lagrangian nature of SPH enables modelling of problems with large deformation and discontinuities, avoiding several disadvantages of the traditional mesh-based methods (e.g. finite element analysis or boundary element methods), and it is also able to implement coupled physics and complex constitutive behaviours due to the history 
tracking ability of the SPH method. As noted in reference [6], SPH has been applied to modelling of fluid flow and thermal problems, but is now being applied to a variety of solid mechanics problems. Pietraszkiewicz and Konopińska [7] recently reviewed various theoretical, numerical and experimental approaches to modelling, analysis and design of compound shell structures with junctions, including tubular joints. Their review included work that considered stress concentration factors at welds. In the present paper, the influence of multipass welding on the residual stress field near the weld toe has been analysed using a combination of analytical and numerical approaches. Thus the weld toe is modelled via a sharp V-notch, where the stress distribution in that crack initiation zone is singular and, under linear-elastic plane-stress or plane-strain conditions, follows the William's solution [1], with the singularity degree depending on the V-notch opening angle. Under elasticplastic conditions the stress distribution ahead of sharp V-notches is still singular but in this case the singularity degree depends also on the power-law used to model hardening of the material [2-6]. In both cases, the intensity of such asymptotic stress fields is quantified by the well-known notch stress intensity factor (NSIF) that is widely used in published literature as a local parameter that is able to summarize the high cycle fatigue strength of welded joints having very different geometries [7-11]. In such previous work, the NSIF was correlated only with external load and geometry without including the influence of residual stresses. This occurred because residual stresses are difficult to quantify either numerically or experimentally. Improved numerical models require all relevant physical, metallurgical and mechanical phenomena to be included and correctly modelled [12-14]. Thermomechanical properties are function of both temperature and metallurgical phases and the 'transformation plasticity' phenomenon [15-17] cannot be ignored [18]. Moreover, the high mesh densities that are required to capture the sharp thermal gradients induced by the welding source, further aggravate the computational complexity of the transient non-linear numerical analysis.

Simplistically, the fusion zone can be modelled using thermal sources of suitable shape, calibrated by means of a preliminary experimental analysis. In practical terms, the heat source is a power density distribution function whose shape varies according to the welding technology employed in making the joint [18]. In particular, for arc welding processes, a double ellipsoid shape heat source is the most realistic [19], whilst for high power density processes, such as laser, plasma or electron beam, a conical heat source shape with a Gaussian power density distribution is preferred. A combination of conical and spherical heat source may also be used in order to simulate the effect of the 'plume' on the fusion zone shape [18]. Finally, the use of an appropriate heat power density distribution to model the weld pool shape has the advantage of easy simulation of filler metal deposition in a multipass welding process by means of the activation/deactivation of elements.

Although modern experimental techniques such as neutron diffraction and synchrotron X-ray diffraction allow high-resolution three dimensional evaluation of the residual stress distribution at welded joints [23], they remain expensive and often difficult to access or apply in real industrial situations. Hence it is still the case that the most commonly used approaches to prediction of the fatigue life for welded joints (i.e. the nominal stress method [24-30], structural stress methods such as hot spot stress [29-31], and local methods such as the notch approach [28-30]) do not consider the real values and distribution of residual stress and consequently are very conservative in the high cycle fatigue $(\mathrm{HCF})$ regime.

Despite the difficulty in measuring or calculating residual stress distributions in welded joints, such distributions are highly influential in determining the fatigue strength of welded joints in the HCF regime [32-33]. It is therefore imperative to develop methods of analysis that can include the effect of residual stresses on the fatigue life of welded joints. In the work of Mochizuchki et al. [34], for example, the residual stresses were treated as mean stresses and their effect on the fatigue strength was taken into account in a modified Goodman diagram. In more recent work, Lopez-Jauregi et al. [35] considered the influence of residual stress in the weld zone by using the critical plane approach proposed by Papadopulos [36] and that was extended some years later to welded structures by Carpinteri [36]. 
In terms of using the local approach based on the NSIF parameter, it has been shown [38-40] that the residual stress distribution near the weld toe is singular and follows the linear-elastic solution proposed by Williams [1] or the elastic-plastic solution described by Lazzarin et al. [7], depending on specimen clamping conditions, material properties and welding parameters. The intensity of such stress field distributions can be quantified using the residual NSIF, which ultimately can be used to extend the local approach to include residual stresses in the prediction of the fatigue life for welded joints [41-44]. In this context, the analysis of the asymptotic residual stress distribution as a function of geometry or welding parameters may be of significant interest in understanding how to improve the fatigue strength of the joint through identifying an optimum set of welding parameters.

In the present work the effect of multipass welding on the residual stress distribution near the weld toe of a butt welded joint has been investigated. Due to the high computational cost of a non-linear transient numerical analysis, a 2-D model using generalized plain strain conditions has been developed. For a fixed plate thickness, the model has been employed to calculate and compare the residual stress distributions arising from single, double and triple pass welding.

\section{Stress field in the vicinity of a sharp V-notch}

Under the assumption of linear-elastic plane-stress or plane-strain conditions, the analytical expression for the stress field in the vicinity of a sharp V-notch tip was given by Williams, for both Mode I and Mode II loading [1]. Employing only the first term of the Williams' expansion series in Mode I loading of the V-notch, the stress field around the notch tip (Fig. 1) can be described by the following equation (1):

$$
\sigma_{i j}(r, \theta)=\frac{K_{1}^{N}}{r^{1-\lambda_{1}}} f_{i j}^{I}(\theta) \quad(i, j=r, \theta)
$$

where $f_{i j}(\theta)$ are the angular functions (which have closed form expressions [45]), $\lambda_{1}$ is the first eigenvalue obtained from Eq. (2),

$$
\lambda \sin (2 \alpha)+\sin (2 \alpha \lambda)=0
$$

and $K_{l}^{N}$ is the NSIF due to a thermal or mechanical symmetrical load (opening Mode I) that is calculated according to Gross and Mendelson's definition [46]:

$$
K_{1}^{N}=\sqrt{2 \pi} \lim _{r \rightarrow 0} r^{1-\lambda_{1}} \sigma_{\theta \theta}(r, \theta=0)
$$

The first eigenvalue depends only by the V-notch angle $(2 \alpha)$ and varies in a range between 0.5 (when $2 \alpha=0$ ) and 0.757 (when $2 \alpha=5 \pi / 6)$ [45] so that Eq. (1) contains a singular term $\left(r^{\lambda_{1}-1}\right.$ when $\left.r \rightarrow 0\right)$. 


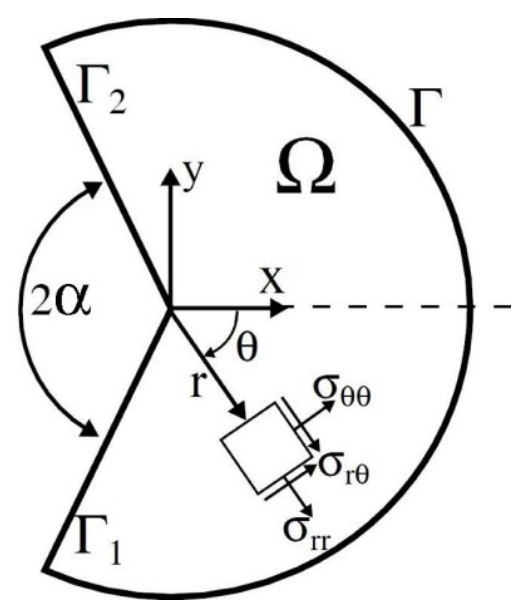

Fig. 1 - Domain $\Omega$ for the sharp V-notch problem

\section{Numerical model description}

In this work, a butt-welded joint was analysed using the numerical code Sysweld ${ }^{\circledR}$. The two plates being joined were modelled with a width (W) equal to $70 \mathrm{~mm}$ and a thickness (H) of $6 \mathrm{~mm}$ irrespective of the number of weld passes (Fig. 2). The weld toe was modelled as a sharp, zero radius, V-shaped notch with an opening angle $(2 \alpha)$ equal to $135^{\circ}$ (Fig. 2). In order to analyse the effect of multipass welding on the residual asymptotic stress field induced near the notch tip, cases of single, double and triple -pass welding were simulated.

The parent plate (or base metal, BM) was modelled as a carbon steel whose chemical composition matched that of the Standard ASTM SA 516 (Grade 65 resp. 70) (Table 1); while the filler metal (FM) was modelled to match the chemical composition shown in Table 2.

\begin{tabular}{ccccccccccc}
\hline $\mathrm{C}$ & $\mathrm{Mn}$ & $\mathrm{Si}$ & $\mathrm{P}$ & $\mathrm{S}$ & $\mathrm{Cr}$ & $\mathrm{Ni}$ & $\mathrm{Cu}$ & $\mathrm{Cr}+\mathrm{Ni}+\mathrm{Cu}$ & $\mathrm{Nb}$ & $\mathrm{Al}_{\text {all }}$ \\
\hline max. & max. & max. & max. & max. & $\max$. & $\max$. & $\max$. & $\max$. & & Min. \\
\hline 0.18 & 1.6 & 0.55 & 0.035 & 0.035 & 0.3 & 0.3 & 0.3 & 0.7 & $0.02-0.08$ & 0.015 \\
\hline+0.03 & +0.05 & +0.05 & +0.005 & +0.005 & \multicolumn{7}{c}{ Allowable variation } \\
\hline
\end{tabular}

Table 1 - Base metal chemical composition (wt $\%)$

\begin{tabular}{ccccccccccc}
\hline $\mathrm{C}$ & $\mathrm{Mn}$ & $\mathrm{Si}$ & $\mathrm{P}$ & $\mathrm{S}$ & $\mathrm{Cr}$ & $\mathrm{Ni}$ & $\mathrm{Cu}$ & $\mathrm{Al}$ & $\mathrm{Ti}$ & $\mathrm{V}$ \\
\hline 0.105 & 1.2 & 0.615 & 0.01 & 0.016 & 0.05 & 0.09 & 0.245 & 0.05 & 0.02 & 0.03 \\
\hline
\end{tabular}

Table 2 - Filler metal chemical composition (SG 2 in accord with German standard) (wt $\%$ ) 


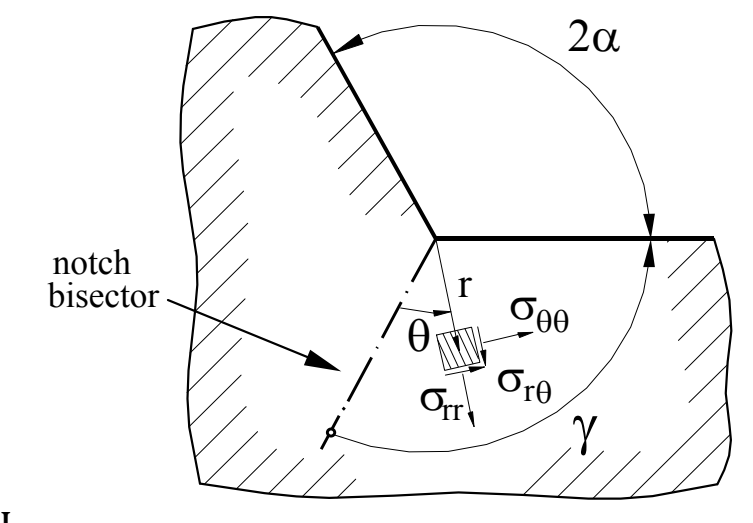

$\mathrm{L}$

Fig. 2 - Schematic representation of the butt-welded joint analysed in this work and the polar coordinate system that is centred at the notch tip of the V-notch with opening angle $2 \alpha$.

Radiative (using the Stephan-Boltzman law) and convective heat loss (using a convective heat transfer coefficient equal to $25 \mathrm{~W} / \mathrm{m}^{2} \mathrm{~K}$ ) were applied at the boundary of the plates to be joined. Thermo-metallurgical and mechanical properties for the parent plate and filler metal as a function of metallurgical phase and temperature were taken from the Sysweld Toolbox 2011® [47]. In the metallurgical analysis the following phases were included: martensite, bainite and ferrite-pearlite for the parent plate; tempered martensite, tempered bainite and austenite for the filler metal. The simplifying assumptions were made that tempered bainite has the same properties as ferrite and that tempered martensite is similar in properties to bainite. The metallurgical transformations mainly depend on thermal history with this dependence described by continuous cooling transformation (CCT) diagrams, which plot the start and end transformation temperatures as a function of cooling rate or cooling time. In the present work the diffusion-controlled phase transformations and the displacive martensitic transformation are modeled by means of the Leblond-Devaux kinetic law [48] and the Koistinen-Marburger law [49], respectively. Fig. 3 shows the CCT diagrams for the parent plate (Fig. 3a) and filler metal (Fig. 3b) that were implemented in the model. 

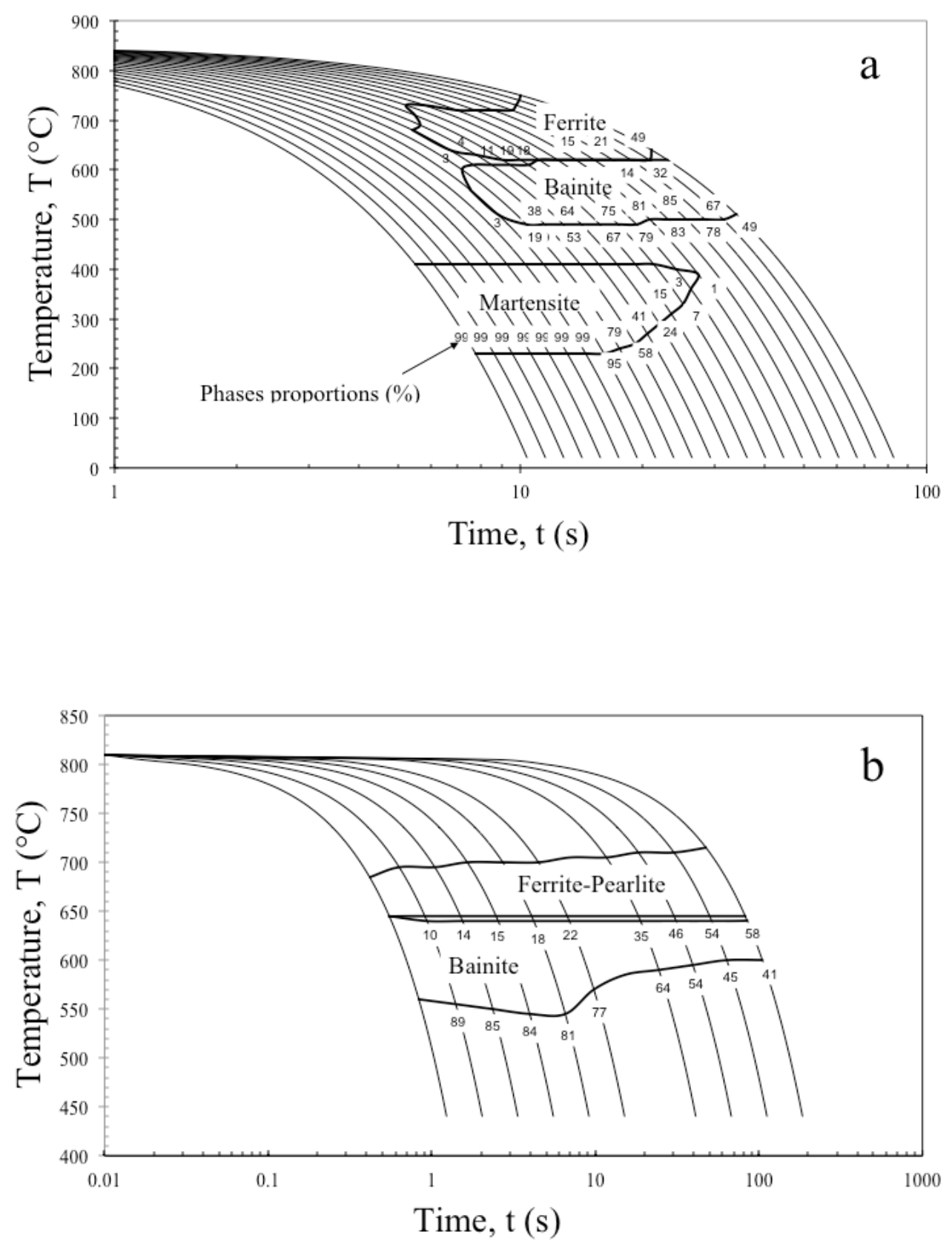

Fig. 3 - CCT diagrams: a) Parent plate, b) Filler metal

Thermal energy flow into the material during the welding is the only computational modelling load in the welding simulation. The amount of thermal energy flow into the material is determined by the welding parameters (including welding speed) and by the welding technology used. In this work the heat source was modelled using a double ellipsoid power density distribution function given by Goldak-Chakravarti [22] (Eq. 4) that has been used in published literature for arc welding simulation [15].

$$
\mathrm{q}_{\mathrm{g}}(\mathrm{x}, \mathrm{y}, \mathrm{t})=\frac{6 \sqrt{3} \mathrm{f}_{1,2} \mathrm{Q}}{\pi \sqrt{\pi} \mathrm{abc} \mathrm{c}_{1,2}} \mathrm{e}^{-\frac{3 \mathrm{x}^{2}}{\mathrm{a}^{2}}} \mathrm{e}^{-\frac{3 \mathrm{y}^{2}}{\mathrm{~b}^{2}}} \mathrm{e}^{-\frac{3[\mathrm{v}(\tau-\mathrm{t})]^{2}}{\mathrm{c}_{1,2}}}
$$


Fig. 4 shows the double ellipsoid heat source configuration while the meaning of symbols in Eq. (4) and their values are summarized in Tables 3 and 4. Introduction of a moving thermal source in the computational model requires a local coordinate system to be created, where the amount of thermal energy flow into the material depends upon the distance from the centre of welding.

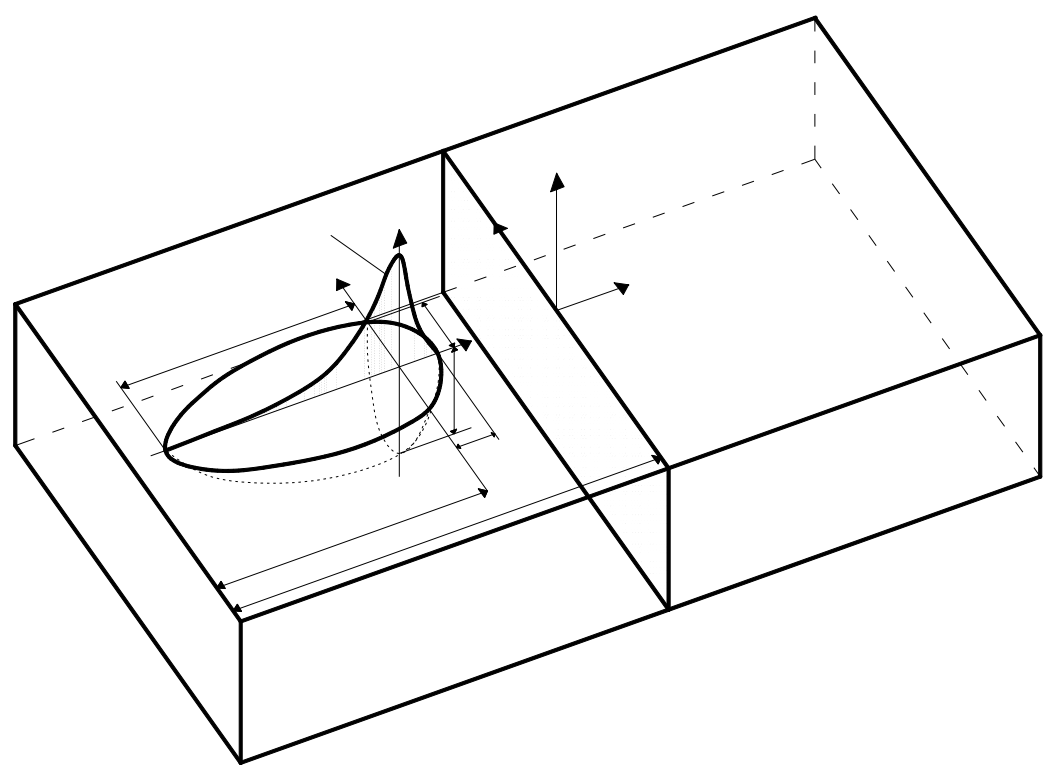

Fig. 4. Double ellipsoid heat source configuration together with the power distribution function along the $\xi$ axis of the moving coordinate system $(x, y, \xi)$. The transformation relating the fixed and the moving coordinate system is $\xi=\mathrm{z}+\mathrm{v}(\tau-\mathrm{t})$.

\begin{tabular}{clc}
\hline $\mathrm{Q}^{*}$ & Power input [W] & $*$ \\
$\eta$ & Efficiency & 0.64 \\
$\mathrm{Q}$ & Absorbed power [W], with $\mathrm{Q}=\eta \mathrm{Q}^{*}$ & - \\
\hline $\mathrm{a}$ & & $*$ \\
$\mathrm{~b}$ & & $*$ \\
$\mathrm{c}_{1}$ & & 2.3 \\
$\mathrm{c}_{2}$ & & 7.9 \\
\hline $\mathrm{f}_{1}$ & & 0.6 \\
$\mathrm{f}_{2}$ & & 1.4 \\
\hline $\mathrm{v}$ & Welding speed $\left[\mathrm{mms}^{-1}\right]$ & 11 \\
$\tau$ & Total time spent by the welding source to be over the transverse & $*$ \\
\hline & cross section of the plate $[\mathrm{s}]$ & \\
\hline
\end{tabular}

Table 3. Goldak's source parameters. *Value depending on welding pass (see Table 4)

By taking advantage of the double symmetry, one half of the joint could be modelled and analysed using approximately 2700 parabolic isoparametric elements. At the notch tip, the minimum size of the elements was about $5 \times 10^{-4} \mathrm{~mm}$. Finally, an uncoupled, thermomechanical analysis was carried out. The activation/deactivation SYSWELD option for elements was used during modelling of welding in order to simulate deposition of filler metal. Activation of elements depends on the welding velocity. The second and third pass elements are non-active during simulation of the first pass. 
Change of activation is done at actual time of welding and the molten/remolten effect is simulated by using a function that clears the history of an element whose temperature exceeds the melting temperature (taken as $1500^{\circ} \mathrm{C}$ ). Table 4 shows the mesh used for each pass together with the source parameters used. It is worth noting that in order to simulate the larger fusion zone and HAZ induced by single-pass welding compared with multipass welding, the fusion metal deposit width (L, Fig. 2) was slightly increased (Table 4).

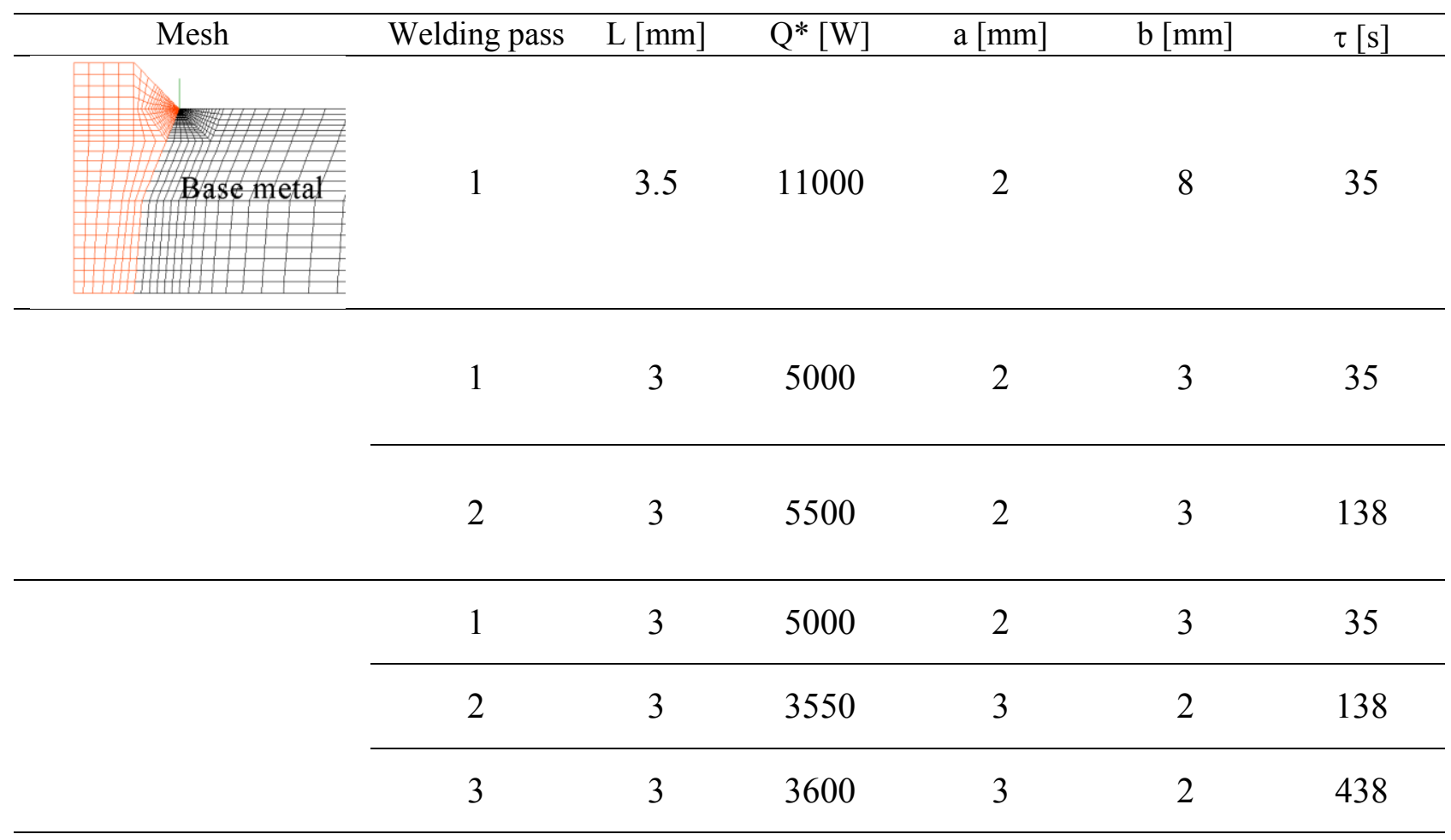

Table 4 - Illustration of the mesh used for the parent plate and filler metal. Heat source parameters (Fig. 4) are also given as a function of welding pass

\section{Results and discussion}

\subsection{Thermo-metallurgical results}

Figures 5, 6 and 7 summarize the most relevant thermo-metallurgical results for single pass, double pass and triple pass welds respectively. Figs 5a, $6 \mathrm{a}$ and $7 \mathrm{a}$ show the temperature distribution at the point when the fusion zone has its maximum width; the fusion zone is shown in red. Figs. $5 \mathrm{~b}, 6 \mathrm{~b}$ and $7 \mathrm{~b}$ show the proportional distribution of the ferrite-pearlite phase after cooling while Figs. 5c, 6c and $7 \mathrm{c}$ show the proportional distribution of the bainite phase after cooling. The interpass temperature was maintained at approximately $100{ }^{\circ} \mathrm{C}$. As indicated in the figures, for both single-pass and multipass welding the room temperature microstructure primarily comprises a mixture of ferriteperlite and bainite. Bainite forms the most prevalent phase in the HAZ in accordance with the CCT diagram. However, a decrease of HAZ width is observed as the number of weld passes increases. This result is consistent with the reduction of heat input (the ratio between the power input and the welding speed, $\mathrm{Q} / \mathrm{v}$ ) that occurs as the number of passes increases. 

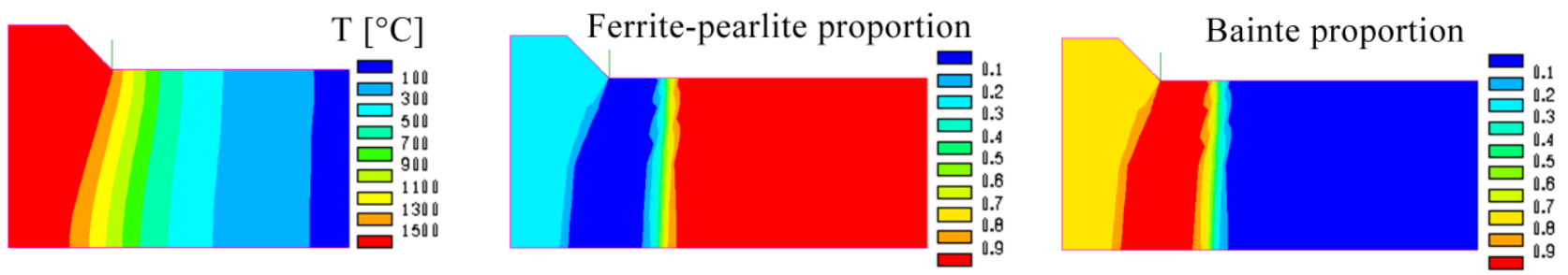

Fig. 5 -Single pass weld: a) Temperature distribution at the instant of maximum fusion zone width; b) Proportional distribution of the ferrite-pearlite phase after cooling; c) Proportional distribution of the bainite phase after cooling.
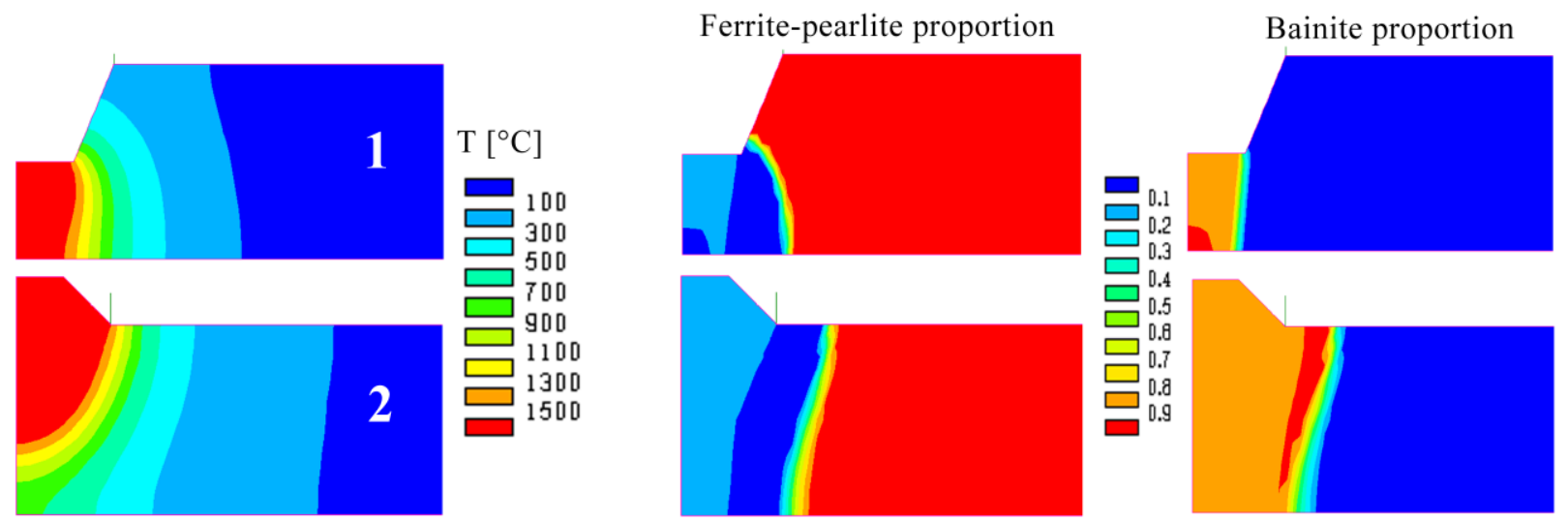

Fig. 6 - Double pass weld: a) Temperature distribution at the instant of maximum fusion zone width; b) Proportional distribution of the ferrite-pearlite phase after cooling; c) Proportional distribution of the bainite phase after cooling.
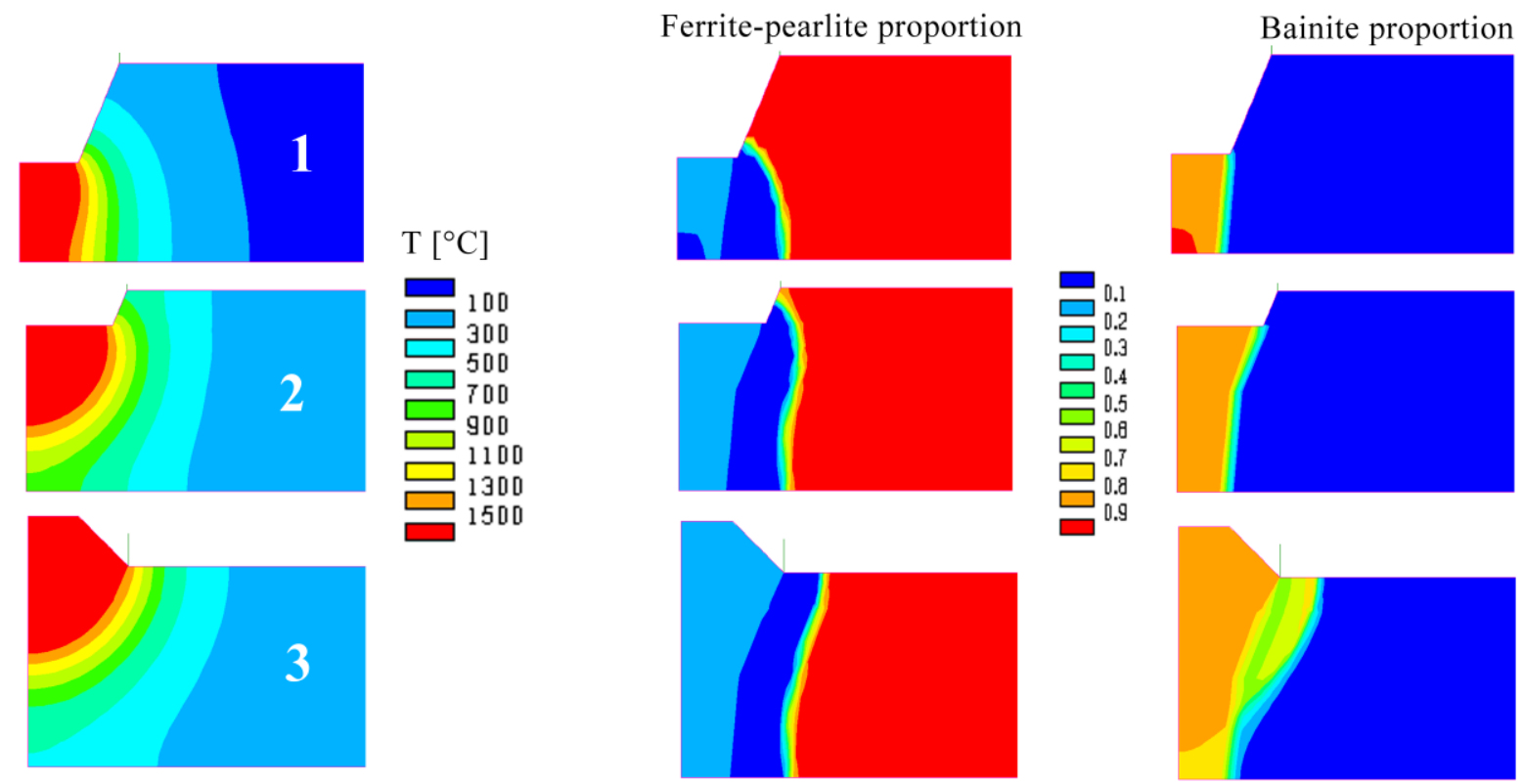

Fig. 7 - Triple pass weld: a) Temperature distribution at the instant of maximum fusion zone width; b) Proportional distribution of the ferrite-pearlite phase after cooling; c) Proportional distribution of the bainite phase after cooling. 


\subsection{Residual stress results}

Figure 8 shows the asymptotic nature of the local residual stress field near the weld toe in the case of double-pass welding. Similar results were obtained in the single and triple-pass welding simulation.

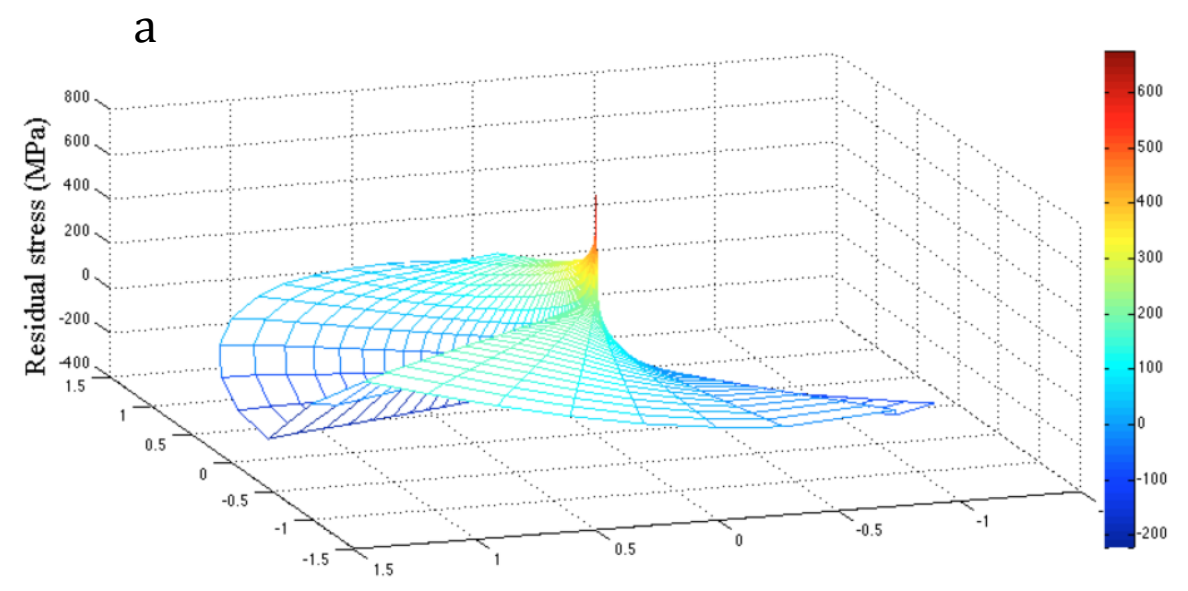

$\mathrm{b}$

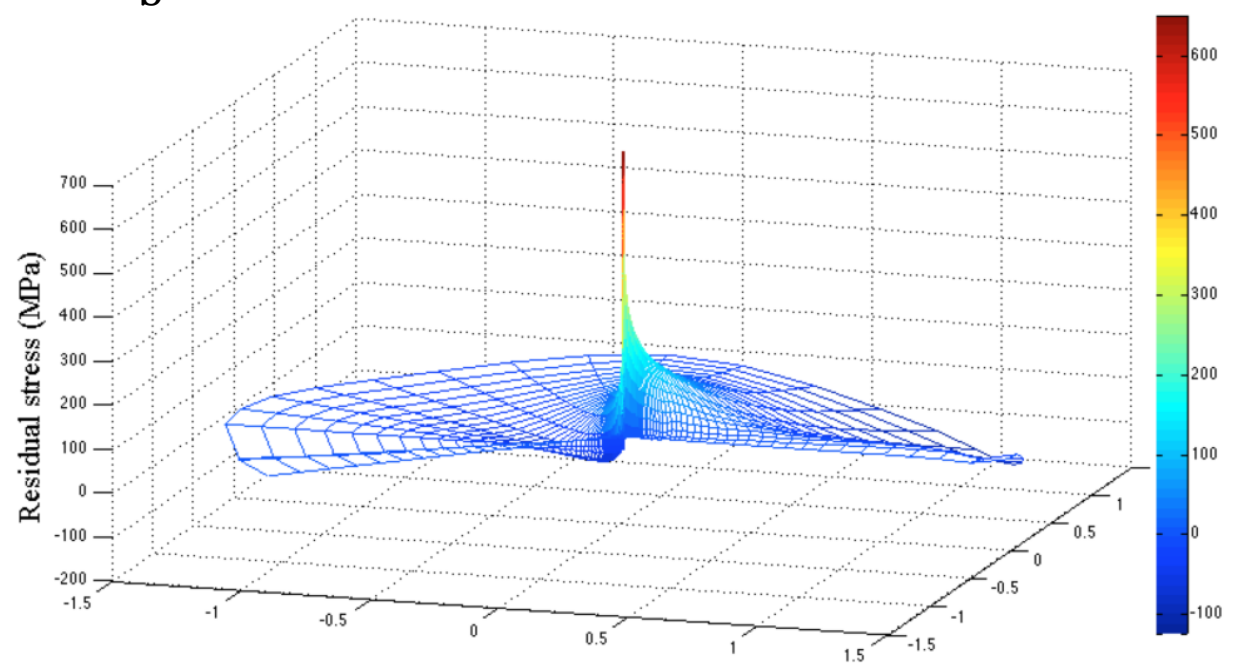

Fig. 8 - Residual stress distribution near the weld toe induced by the double-pass welding; a) $\sigma_{\mathrm{rr}}, \mathrm{b}$ ) $\sigma \theta \theta$

The stress distribution in the neighborhood of the weld toe is linear in a log-log plot (Fig. 9) and its slope corresponds to the analytical solution given by Williams [1] (Eq. (1)). Due to the mixed mode loading, the accurate analytical solution should contain also a Mode II component that is not singular for the V-notch opening angle case considered in this work. However, the Mode I term dominates the stress field in the near-tip region and hence the Mode II component need not be taken into account to a first order approximation. Fig. 9 shows the asymptotic $\sigma_{\theta \theta}$ component of the residual stress field near the notch tip along the plane bisecting the notch angle, i.e. $\theta=0^{\circ}$. 


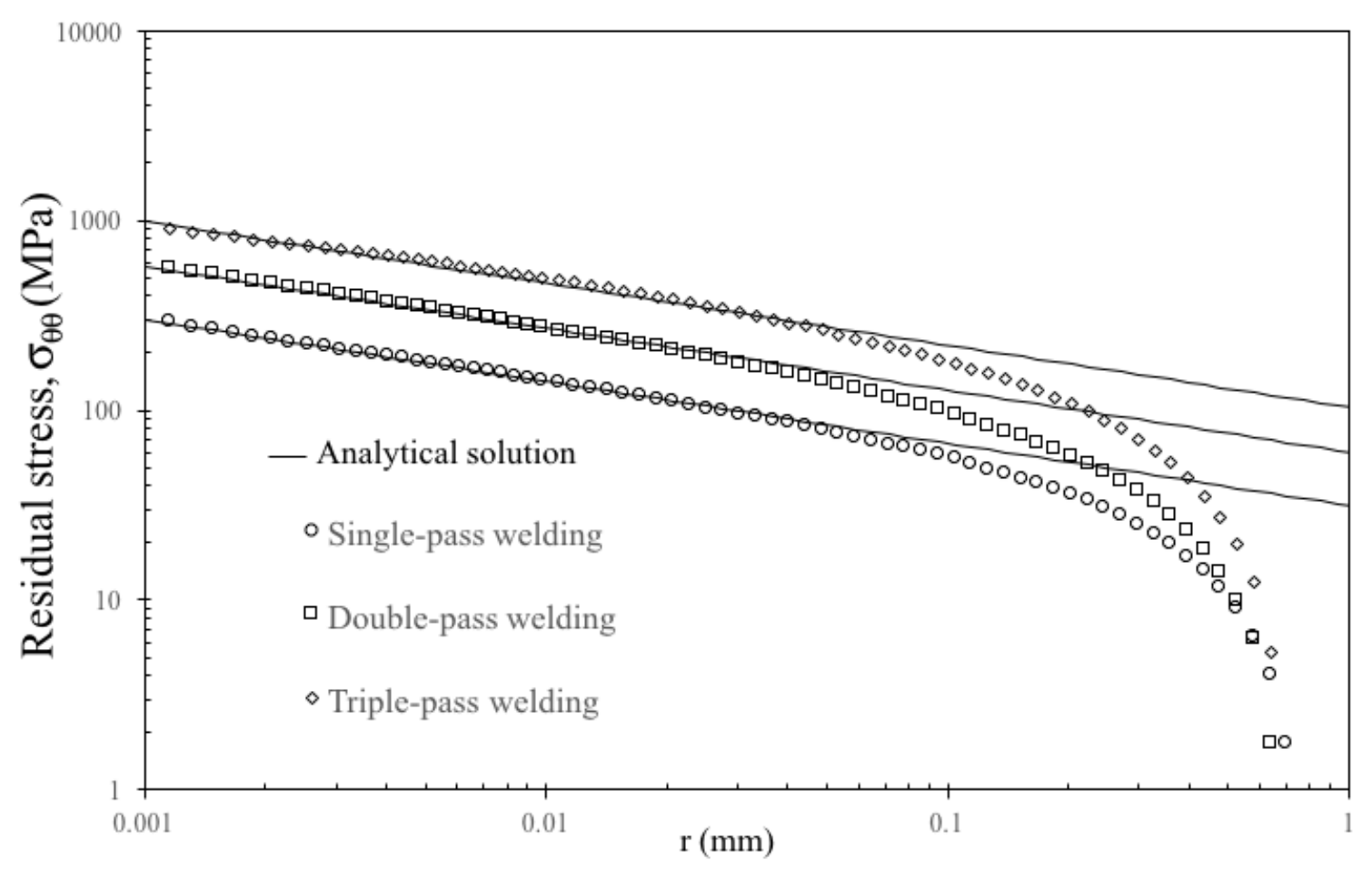

Fig. 9 - Asymptotic $\sigma_{\theta \theta}$ component of the residual stress field near the notch tip along the plane bisecting the notch angle, i.e. $\theta=0^{\circ}$.

Since the local residual stresses are found to lie in the elastic range, it is possible to compare their distributions in terms of residual NSIF according to the number of passes; in particular, Fig. 9 shows that the higher the number of passes, the higher is the intensity of the asymptotic stress distribution. Table 5 summarises the residual NSIF values calculated for each pass number. There is a significant increase in residual NSIF with increase in number of weld passes. This phenomenon can be explained in terms of fusion zone width obtained in the final welding pass in each case. For a fixed plate thickness, the decrease in size of the fusion zone increases the degree of constraint to which the joint is subjected during solidification of the molten region (Figs. 5, 6, 7) and, as a consequence, the intensity of the residual stress field increases.

On the basis of the model previously developed and validated by the present authors [41-44] that quantifies the influence of residual stresses on fatigue strength of either welded joints or pre-stressed notched components (see Eq. 5), a reduction in HCF strength is expected as the number of passes increases:

$$
\Delta \sigma_{n}=\frac{R_{C}^{1-\lambda_{I}}\left[\frac{E}{e_{I}}\left(\frac{C}{N}\right)^{1 / z}\right]^{1 / 2}}{k_{I} h^{1-\lambda_{I}}}-\frac{K_{I}^{r e s}}{k_{I} h^{1-\lambda_{I}}}
$$

In Eq. (5) $\Delta \sigma_{\mathrm{n}}$ is the nominal stress amplitude, $\mathrm{E}$ is the elastic modulus, $\mathrm{C}$ is a constant and $\mathrm{z}$ is the slope of the fatigue data expressed in terms of experimentally calculated local strain energy density [41]; $\mathrm{h}$ is the plate thickness, $\mathrm{k}_{\mathrm{I}}$ is a non-dimensional coefficient, analogous to the shape functions of cracked components [8]. $R_{c}$ is a material constant which represents the critical radius of a circular sector, centred on the notch tip, over which the strain energy density is averaged. Finally, $e_{I}$ is a 
parameter which depends on V-notch opening angle $(2 \alpha)$, Poisson's ratio $(v)$ and the failure hypothesis adopted. It is worth mentioning that in $\mathrm{Eq}(5)$ the load ratio (R) is taken to be 0 .

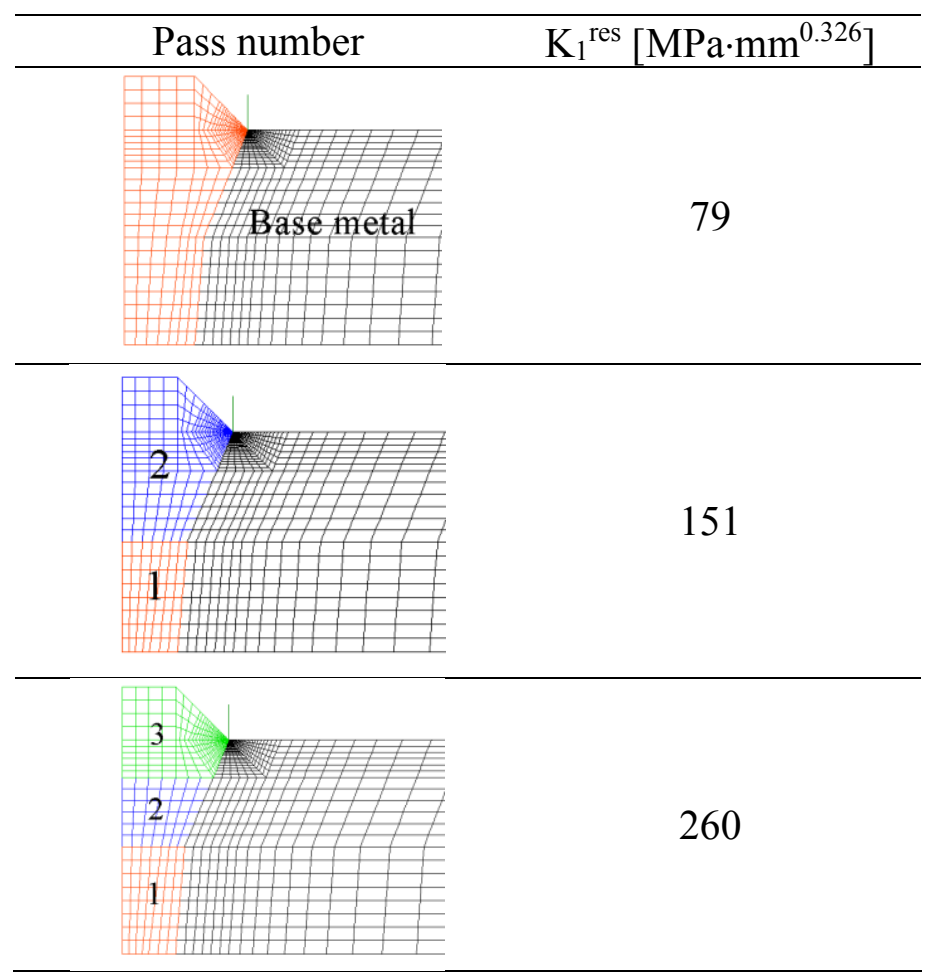

Table 5 - Residual NSIF $\left(\mathrm{K}_{1}{ }^{\text {res }}\right)$ value as a function of the deposits number

\section{Conclusions}

The effect of multipass welding on the residual asymptotic stress field ahead of the weld toe has been numerically studied in this paper. Single-pass, double-pass and triple-pass welding were numerically simulated for a fixed plate thickness, using a 2D model which takes into account all the physical, metallurgical, thermal and mechanical phenomena involved in the welding process. As expected, the higher the number of weld passes, the lower the fusion zone and HAZ width. This leads to the formation of metallurgical phases in the weld zone with better static mechanical properties and lower distortion of the multipass welded joint compared with a single-pass welded joint of the same thickness. However, the lower the fusion zone width induced during the final weld pass, the higher the degree of constraint in the joint during its solidification. This results in an increase of the residual NSIF value with increase in the number of welding passes and a consequent decrease in the expected HCF strength.

\section{References}

[1] Williams, M. L. (1952) Stress singularities resulting from various boundary conditions in angular corners of plates in extension. J. Appl. Mech. 19, 526-528.

[2] Hutchinson, J. W. (1968) Singular behaviour at the end of a tensile crack in a hardening 
material. J. Mech. Phys. Solids 16, 13-31.

[3] Rice, J. R. and Rosengren, G. F. (1968) Plane strain deformation near a crack tip in a powerlaw hardening material. J. Mech. Phys. Solids 16, 1-12.

[4] Ponte Castan eda, P.(1985) Asymptotic fields in steady crack growth with linear strainhardening. J. Mech. Phys. Solids 35, 227-268.

[5] Xia, L. and Wang, T. (1993) Singular behavior near the tip of a sharp V-notch in a powerhardening material. Int. J. Fracture 59, 83-93.

[6] Yuan, H. and Lin, G. (1994) Analysis of elastoplastic sharp notches. Int. J. Fracture 67, 187216.

[7] Lazzarin, P., Zambardi, R. and Livieri, P. (2001) Plastic notch stress intensity factors for large V-shaped notches under mixed load conditions. Int. J. Fracture 107, 361-377.

[8] Lazzarin, P. and Tovo, R. (1998) A notch intensity approach to the stress analysis of welds. Fatigue Fract. Engng. Mater. Struct. 21, 1089-1104.

[9] Atzori, B., Lazzarin, P. and Tovo, R. (1999) From the local stress approach to fracture mechanics: a comprehensive evaluation of the fatigue strength of welded joints. Fatigue Fract. Engng. Mater. Struct. 22, 369-381.

[10] Lazzarin, P. and Livieri, P. (2001) Notch Stress Intensity Factors and fatigue strength of aluminium and steel welded joints. Int. J. Fatigue 23, 225-232.

[11] Atzori, B. and Meneghetti, G. (2001) Fatigue strength of fillet welded structural steels: finite elements, strain gauges and reality. Int. J. Fatigue 23, 713-721.

[15] P. Ferro, F. Bonollo, A. Tiziani, 2010. 'Methodologies and experimental validations of welding process numerical simulation'. Int. J. Computational Materials Science and Surface Engineering, Vol. 3, Nos. 2/3, pp. 114-132

[16] P. Ferro, F. Bonollo, A. Tiziani, 2005. 'Laser welding of copper-nickel alloys: a numerical and experimental analysis'. Science and Technology of Welding and Joining, Vol 5 No 3, pp 299-310

[17] P. Ferro. "The use of Matlab in the advanced design of bonded and welded joints". Book: Applications of MATLAB in Science and Engineering, Chapter 19, Edited by: Tadeusz Michałowski, ISBN 978-953-307-708-6, September 2011, pp. 387-408.

[18] Leblond, J.B., Mottet, G. and Devaux, J.C. (1986a) 'A theoretical and numerical approach to the plastic behaviour of steels during phase transformations - I. Derivation of general relations', Journal of the Mechanics and Physic of Solids, Vol. 34, No. 4, pp.395-409.

[19] Leblond, J.B., Mottet, G. and Devaux, J.C. (1986b) 'A theoretical and numerical approach to the plastic behaviour of steels during phase transformations - II. Study of classical plasticity for ideal-plastic phases', J. Mech. Phys. Solids, Vol. 34, No. 4, pp.411-432.

[20] Leblond, J.B., Mottet, G. and Devaux, J.C. (1989) 'Mathematical modelling of transformation plasticity in steels I: case of ideal-plastic phases', International Journal of Plasticity, Vol. 5, No. 4, pp.551-572.

[21] P. Ferro, H. Porzner, A. Tiziani, F. Bonollo, 2006. 'The influence of phase transformations on residual stresses induced by the welding process - 3D and 2D numerical models'. Modelling Simul. Mater. Sci. Eng. 14 (2006) 117-136

[22] Goldak, J., Chakravarti, A. and Birbby, M. (1984) A new finite element model for welding heat sources. Metallur. Trans. B 15b, 299-305.

[23] James, M. N., Hughes, D. J., Chen, Z., Lombard, H., Hattingh, D. G., Asquith, D., Yates, J. R. and Webster, P. J. (2007) Residual stresses and fatigue performance. Eng. Failure Anal. 14, 384-395.

[24] BS BS7608. Code of practice for fatigue design and assessment of steel structures. British Standards Institution; 1993.

[25] Offshore technology report 2001/015. Steel; 2002.

[26] Eurocode 3: Design of steel structures - part 1-9: Fatigue; 2005.

[27] DNVeritas. Fatigue design of offshore steel structures. DNV Recommended Practice DNV- 
RP-C203; 2010.

[28] Haibach E. Analytical strength assessment of components in mechanical engineering. VDMA-Verlag; 2003.

[29] Radaj D, Sonsino CM, Fricke W. Fatigue assessment of welded joints by local approaches. Woodhead publishing; 2006.

[30] Bruder T, Störzel K, Baumgartner J, Hanselka H. Evaluation of nominal and local stress based approaches for the fatigue assessment of seam welds. Int J Fatigue 2012;34:86-102.

[31] Fricke W, Kahl A. Comparison of different structural stress approaches for fatigue assessment of welded ship structures. Mar Struct 2005;18:473-88.

[32] Maddox SJ. Fatigue strength of welded structures. Woodhead publishing; 1991.

[33] Kong F, Ma J, Kovacevic R. Numerical and experimental study of thermally induced residual stress in the hybrid laser-GMA welding process. J Mater Process Technol 2011;211:1102-11.

[34] Mochizuki, M., Hattori, T. and Navakano, K. (2000) Residual stress reduction and fatigue strength improvement by controlling welding pass sequences. J. Eng. Mat. Tech. 122, 108112.

[35] A. Lopez-Jauregi, J.A, Esnaola, I. Ulacia, I. Urrutibeascoa, A. Madariaga. Fatigue analysis of multipass welded joints considering residual stresses. Int. J. Fatigue 79 (2015) 75-85

[36] Papadopoulos I. Critical plane approaches in high-cycle fatigue: on the definition of the amplitude and mean value of the shear stress acting on the critical plane. Fatigue Fract Eng Mater Struct 1998;21:269-85.

[37] Carpinteri A, Spagnoli A, Vantadori S. Multiaxial fatigue life estimation in welded joints using the critical plane approach. Int J Fatigue 2009;31:188-96.

[38] P. Ferro, F. Berto, P. Lazzarin, 2006. 'Generalized stress intensity factors due to steady and transient thermal loads with applications to welded joints'. Fatigue Fract. Engng. Mater. Struct, 29 (2006) 440-453.

[39] P. Ferro, N. Petrone, 2009. "Asymptotic Thermal and Residual Stress Distributions due to Transient thermal Loads". Fatigue Fract. Engng. Mater. Struct. 32(11), pp. 936-948.

[40] P. Ferro, 2012. The influence of phase transformations on the asymptotic residual stress distribution arising near a sharp V-notch tip. Modelling Simul. Mater. Sci. Eng. 2012, 20(8).

[41] P. Ferro (2014). The local strain energy density approach applied to pre-stressed components subjected to cyclic load. Fatigue and Fracture of Engineering Materials and Structures. (2014). Vol. 37(11) pp. 1268-1280.

[42] P. Ferro, F. Berto. Quantification of the influence of residual stresses on fatigue strength of Al-alloy welded joints by means of the local strain density approach. Strength of Materials (2016) Volume 48, Issue 3, pp 426-436

[43] P. Ferro, F. Berto, N.M. James. Asymptotic residual stresses in butt-welded joints under fatigue loading. Theoretical and Applied Fracture Mechanics 83 (2016) 114-124

[44] P. Ferro, F. Berto, M.N. James, T. Borsato. Review of recent advances in local approaches applied to pre-stressed components under fatigue loading. 21st European Conference on Fracture, ECF21, 20-24 June 2016. Procedia Structural Integrity (2016) Vol. 2, 3467-3474

[45] Livieri P and Lazzarin P 2005 Fatigue strength of steel and aluminium welded joints based on generalised stress intensity factors and local strain energy values Int. J. Fract. 133 247-76

[46] Gross R and Mendelson A 1972 Plane elastoplastic analysis of V-notched plates Int. J. Fract. Mech 8 267-76

[47] Sysweld Toolbox 2011®

[48] Leblond J B and Devaux J 1984 A new kinetic model for anisothermal metallurgical transformations in steels including the effect of austenite grain size Acta Metall. 32 137-46

[49] Koistinen D P and Marburger R E 1959 A general equation prescribing extent of austenitemartensite transformation in pure iron-carbon alloys and carbon steels Acta Metall. 7 59-68 


\section{MNJ References}

[1] M.N. James, M. Newby, P. Doubell, D.G. Hattingh, K. Serasli, D.J. Smith, Weld residual stresses near the bimetallic interface in clad RPV steel: A comparison between deep-hole drilling and neutron diffraction data, Nuclear Engineering and Design, 274 (2014) 56-65.

[2] S. Murugan, S.K. Rai, P.V. Kumar, T. Jayakumar, B. Raj, M.S.C. Bose, Temperature distribution and residual stresses due to multipass welding in type 304 stainless steel and low carbon steel weld pads, International Journal of Pressure Vessels and Piping, 78 (2001) 307-317.

[3] C. Liu, J.X. Zhang, C.B. Xue, Numerical investigation on residual stress distribution and evolution during multipass narrow gap welding of thick-walled stainless steel pipes, Fusion Engineering and Design, 86 (2011) 288-295.

[4] Y. Ueda, H. Murakawa, N. Ma, Chapter 7 - Strategic Simulation Analyses for Manufacturing Problems Related to Welding, in: Welding Deformation and Residual Stress Prevention, Butterworth-Heinemann, Boston, 2012, pp. 209-246.

[5] H.K.D.H. Bhadeshia, Developments in martensitic and bainitic steels: role of the shape deformation, Materials Science and Engineering: A, 378 (2004) 34-39.

[6] R. Das, P.W. Cleary, Three-dimensional modelling of coupled flow dynamics, heat transfer and residual stress generation in arc welding processes using the mesh-free SPH method, Journal of Computational Science, 16 (2016) 200-216.

[7] W. Pietraszkiewicz, V. Konopińska, Junctions in shell structures: A review, Thin-Walled Structures, 95 (2015) 310-334. 